\title{
Topografias afetivas na ficção de Chico Buarque
}

\section{Affective Topographies in Chico Buarque's Prose}

\author{
Gabriel Borowski \\ Universidade Jaguelônica de Cracóvia \\ gabriel.m.borowski@gmail.com
}

\begin{abstract}
This text is an attempt to discuss the affective dimension of the experience of the city in three novels by the Brazilian writer and composer Chico Buarque. In Estorvo (1991) the protagonist is unable to create bonds with the urban space and his perception of the city is a blend of actual observation and his delirious subjectivity. In Budapeste (2004) the main character is experiencing the capital of Hungary as an affective representation of the actual place. In Leite derramado (2009) the narrator is organising his story through affective memories of significant places.
\end{abstract}

Keywords: affective topography, contemporary Brazilian fiction, geopoetics, Chico Buarque

\section{INTRODUÇÃO: SONÂMBULOS BUARQUEANOS ${ }^{1}$}

O primeiro capítulo do romance Budapeste, publicado em 2003 pelo escritor e compositor brasileiro Chico Buarque, termina no momento em que o protagonista, José Costa, deixa a cidade visitada por acaso devido a um pouso imprevisto no caminho de Istambul a Frankfurt:

Apertei o cinto, fechei os olhos, achei que não ia dormir nunca mais na vida, tomei um sonífero e o avião decolou. Cheguei o rosto à janela, estava tudo nublado, a pílula fazia efeito. Quando se abriu um buraco nas nuvens, me pareceu que sobrevoávamos Buda-

\footnotetext{
${ }^{1}$ As reflexões desenvolvidas neste artigo foram apresentadas incialmente na Faculdade de Letras da Universidade Eötvös Loránd de Budapeste no âmbito do simpósio O Brasil em contexto europeu e húngaro em outubro de 2014.
} 
peste, cortada por um rio. O Danúbio, pensei, era o Danúbio mas não era azul, era amarelo, a cidade toda era amarela, os telhados, o asfalto, os parques, engraçado isso, uma cidade amarela, eu pensava que Budapeste fosse cinzenta, mas Budapeste era amarela (Buarque, [2003] 2008, p. 12).

Como se vê neste trecho, a descrição da capital húngara e da sua cor inesperada se realiza sob o efeito de um sonífero, quando as fronteiras entre a percepção e a imaginação se dissolvem. Percebe-se, em uma leitura mais atenta, que a visão nublada que se tem da cidade pode ser atribuída tanto às circunstâncias externas, meteorológicas, quanto ao estado interno, mental, do protagonista, que depois de tomar o sedativo começa a cair no sono. Não se sabe se a última parte da segunda frase ("cheguei o rosto à janela, estava tudo nublado, a pílula fazia efeito") sinaliza a relação temporal (de simultaneidade ou consequência), ou antes tem caráter explicativo, indicando o motivo da percepção perturbada de Budapeste.

Convém observar que este estado de "onirismo desperto" (Silva, 2004, p. 119), que no caso supracitado inviabiliza reivindicações referenciais que procurem cotejar a imagem da capital húngara com a sua representação na ficção buarqueana, impregna toda a obra romanesca do autor. Aliás, já no romance anterior, intitulado Benjamim, de 1995, o primeiro capítulo também termina com um protagonista que adormece quando "deita-se nu na cama, e entre as penumbras vê Castana Beatriz que passeia à vontade na pele da filha, alguns números maior que a sua" (Buarque, [1995] 1997, p. 21). Do mesmo modo, talvez não seja por acaso que o primeiro capítulo do romance Leite derramado, publicado por Chico Buarque em 2009 e narrado por um idoso alucinado e sob efeito de morfina, encerra-se com uma passagem muito parecida com a sequência de Budapeste:

Sirene na rua, telefone, passos, há sempre uma expectativa que me impede de cair no sono. É a mão que me sustém pelos raros cabelos. Até eu topar na porta de um pensamento oco, que me tragará para as profundezas, onde costumo sonhar em preto-e-branco (Buarque, 2009, p. 12).

Também no romance mais recente do autor, $O$ irmão alemão, lançado em 2014, o primeiro capítulo termina precisamente no momento em que as fronteiras entre o presente e o passado, a realidade e o sonho, se dissolvem:

(...) penava para compreender O Ramo de Ouro até achar o bilhete alemão, bilhete que aliás me leva a lembrar que o Thelonious, no tempo em que ainda se chamava Montgomery, andou por aí com outro amigo, um suíço, ou austríaco, (...), e de repente sem mais nem menos estou num Oldsmobile com o Thelonious, que me conduz a um internato chamado Instituto Benjamenta, onde o austríaco, ou suíço, (...) me traduz a carta de Anne bem devagar, me explicando o significado de cada palavra, sua origem, sua etimologia, com uma voz tão suave que nada escuto, o que me leva a cair no sono (Buarque, 2014, p. 13-14). 
Alega-se que esta tendência do autor para a criação de quadros ambientais ambivalentes que oscilam entre o concreto e o abstrato, privilegiando representações de estados liminares e oníricos, se estende para a totalidade da sua produção ficcional autonarrativa. Por isso, no presente artigo se pretende analisar o que se pode considerar "topografias afetivas" na ficção de Chico Buarque. Conjugam-se, neste termo, dois planos que este pequeno estudo procura manter em seus limites. Pela topografia (do grego topos $=$ lugar, e graphein $=$ escrever) se entendem as representações discursivas do espaço - neste caso, dentro da narrativa ficcional. O foco de interesse não recairá, no entanto, na questão de autenticidade do relato romanesco e da correspondência entre o ambiente ficcional e os lugares evocados, uma vez que toda a criação literária implica uma remodelação da realidade empírica. Ao invés disso, as representações do espaço na obra de Chico Buarque serão abordadas na sua dimensão afetiva, tomando esse termo no seu sentido original latino de affectus, isto é, estado da mente ou do corpo produzido por uma influência externa (Etymonline, 2019). Tendo isto em vista, o objeto da análise consistirá nas impressões subjetivas dos personagens buarqueanos - sempre delirantes, alucinados, mentalmente perturbados, desenraizados, flutuantes, incapazes de criar vínculos identitários com o espaço - enquanto afetados pelos lugares percorridos.

O corpus do presente artigo é constituído por três autonarrativas ficcionais de Chico Buarque - ele mesmo "um caminhador [que adora] andar pela cidade" (Peres, 2016, p. 190) - Estorvo (1991), Budapeste (2003) e Leite derramado (2009), nas quais a representação do espaço urbano e sua relação com a disposição mental do sujeito enunciador parecem particularmente sobressalientes. Excluem-se os romances Benjamim (1995), que não relata a experiência do sujeito em primeira pessoa, sendo esta mediada pelo narrador heterodiegético, e a autoficção $O$ irmão alemão (2014), bem como a novela alegórica Fazenda modelo (1971), o livro infantil Chapeuzinho amarelo (1979) e as peças teatrais.

\section{TOPOGRAFIAS AFETIVAS}

O emprego do termo "topografia afetiva" utilizado neste artigo corresponde, embora não se deva, à proposta de Ian Walker (2002) no estudo City Gorged with Dreams: Surrealism and documentary photography in interwar Paris ${ }^{2}$. Discutindo a representação fotográfica da cidade de Paris no livro Nadja, de 1928, de André Breton, o pesquisador afirma:

\footnotetext{
${ }^{2}$ Recentemente o mesmo termo foi utilizado também por David Anderson (2017) em sua tese de doutorado intitulada Affective Topographies: Landscape and Subjectivity in the Work of Patrick Keiller, W.G. Sebald and Iain Sinclair e por Ji-Yeon O. Jo (2018) no estudo Homing: An Affective Topography of Ethnic Korean Return Migration.
} 
A private city has been created within the public city, occupying the same space, but differently, more intensely. The physical geography of Paris is replaced by an affective topography, superimposing a sort of carte $d u$ tendre over the actual city. Or, to project forward, Nadja can be seen as an exemplification of 'psychogeography' - the concept employed by the Situationists in the 1950s to describe a condition where aspects of the actual city and our subjective response to it have become fused and can no longer be separated (Walker, 2002, p. 53-55).

A intensidade da experiência subjetiva do espaço, que para Walker se coloca no centro da reflexão, constitui um dos aspetos realçados pelas pesquisas no âmbito da chamada "teoria dos afetos", desenvolvida desde meados dos anos 1990 (Nader, 2014a; Nycz, 2014) apesar de fortes críticas (Leys, 2011).

O conceito central para essa proposta, o "afeto", como sublinha Luiza Nader (2014b, p. 20), carece ainda de uma definição consensual e as potencialidades de seu emprego ainda não foram suficientemente discutidas. Em seu ensaio seminal, Brian Massumi (1995) defende a distinção entre as noções de afeto e de emoção, sendo esta mais portadora de um conteúdo qualitativamente identificável (como "intensity owned and recognized", p. 88), enquanto o afeto é antes uma uma "protoemoção" (Nader, 2014a, p. 31), uma intensidade reconhecível sobretudo através de seus efeitos sobre o sujeito (Massumi, 1995, p. 107, nota 2), uma abertura ao mundo exterior (Nycz, 2014). Nesse âmbito, um instigante campo de estudo concerne à dimensão afetiva do espaço, e do espaço urbano em particular, pois, segundo Nigel Thrift (2004):

Cities may be seen as roiling maelstroms of affect. Particular affects such as anger, fear, happiness and joy are continually on the boil, rising here, subsiding there, and these affects continually manifest themselves in events which can take place either at a grand scale or simply as a part of continuing everyday life (p. 57).

Uma análise do modo como a cidade afeta os sujeitos pode levar a uma reflexão com escopo maior, dado que "a reflexão sobre a cidade é basicamente uma reflexão sobre a cultura" (Rybicka, 2006, p. 472, tradução minha). Assim, por exemplo, Michel de Certeau ([1980] 1998) em $A$ invenção do cotidiano considera a cidade "o mais desmesurados dos textos humanos" (p. 170), no qual o corpo está "enlaçado pelas ruas que o fazem rodar e girar segundo uma lei anônima" e "possuído, jogador ou jogado, pelo rumor de tantas diferenças e pelo nervosismo do tráfego" (p. 170), obedecendo "aos cheios e vazios de um 'texto' urbano que escrevem sem poder lêlo" (p. 171). A experiência da cidade é, portanto, um processo recíproco em que "a prática" e a percepção do espaço se fundem, um fenômeno corporal e afetivo, focado no próprio ato de perambulação enquanto uma "apropriação do sistema topográfico pelo pedestre" (p. 177). Na crítica brasileira mais recente, uma excelente revisão das relações entre as categorias de afeto, espaço urbano, e, neste caso, 
também o conceito do gênero na literatura contemporânea, pode ser encontrado no artigo de Sandra Regina Goulart Almeida (2015), em que a pesquisadora afirma:

As teorizações sobre os afetos abrem espaço para pensarmos as mobilidades contemporâneas não apenas em termos geográficos, mas também em relação à circulação de emoções e afetos entre determinados corpos, levando a ações e reflexões éticas que decorrem da maneira como os corpos são afetados, numa perspectiva ética, pelos espaços contemporâneos e por outros sujeitos que por eles circulam (p. 25).

\section{ESTORVO (1991)}

O enredo do primeiro romance de Chico Buarque, Estorvo, reduz-se essencialmente a uma fuga constante: depois de ver um desconhecido tocando sua campainha, o protagonista (anônimo) sai de seu apartamento e procura ajuda na casa de sua irmã, casada com um milionário. Visita o antigo sítio da família, onde se instalaram bandidos plantadores de maconha. Expulso do local, volta à casa da irmã e descobre que a família foi assaltada e a irmã foi estuprada depois de não ter conseguido achar as joias que o protagonista tinha roubado durante a última visita. No final, ele vai com o delegado da polícia ao sítio, onde presencia a execução dos marginais, e acaba fugindo para um ponto de ônibus, onde fica esfaqueado por um desconhecido.

A cidade em que se realiza o enredo não é nomeada. Ainda que se possa supor que o local da ação seja o Rio de Janeiro, é necessário resistir à uma plena identificação da urbe ficcional com a metrópole carioca. $\mathrm{O}$ espaço só existe na medida em que afeta a subjetividade do protagonista - um personagem delirante, incapaz de decifrar os signos encontrados durante a sua perambulação pela cidade (Nogueira, 2005). O seu maior drama consta na impossibilidade de identificação (de rostos, papéis sociais, intenções etc.) que implica uma incapacidade de construir uma identidade (Borowski, 2012). Se, como se verá mais adiante, o protagonista do romance Budapeste, José Costa, consegue finalmente penetrar no universo dos signos anteriormente incompreensíveis, o protagonista de Estorvo fracassa, e o seu malogro resulta em sua (suposta) morte no final da narrativa.

No romance há poucas referências a lugares específicos. A paisagem urbana retratada no romance existe sobretudo enquanto um espaço em que a modernização resulta num apagamento da singularidade: "Ando no meio do povo em linha reta, mas parece que cruzo sempre com as mesmas pessoas. E essas pessoas também parecem me admirar, me vendo passar tão repetido" (Buarque, 1991, p. 23). O protagonista observa muitas vezes corpos desintegrados que se confundem com o espaço eclético da cidade, como na cena dentro de um centro comercial:

Invejo um pouco as cabeças que despontam no vão, que sobem curiosas uma atrás da obra na escada rolante, cabeças que esticam o pescoço e vão criando corpo, e criam pés 
que saltam na sobreloja, e viram pessoas que agitam cabeças que falam, piscam, riem e mastigam triângulos de pizza por ali. (Buarque, 1991, p. 37).

Nesta e em outras sequências se entende que a percepção do espaço urbano é moldada pelo estado afetivo do personagem principal, dado que a fragmentação do sujeito se reflete na fragmentação da representação da cidade. Há uma tensão entre a população urbana e o protagonista: "Vejo a multidão fechando todos os meus caminhos, mas a realidade é que eu sou o incômodo no caminho da multidão" (Buarque, 1991, p. 106). O espaço público é portanto um espaço opressivo, em que o narrador não consegue se fixar, imergir na turba urbana. É precisamente um estorvo.

O protagonista renuncia a necessidade de inscrição, de criação de vínculos identitários com o espaço. Essa atitude se evidencia sobretudo no que diz respeito ao antigo sítio da família, relacionado com a infância do protagonista. Paradoxalmente, o que importa não é o local em si, mas antes a sua condição de um antilugar, um lugar capaz de suspender a existência de outros locais:

Encontrar aberta a cancela do sítio me perturba. Penso nos portões dos condomínios, e por um instante aquela cancela escancarada é mais impenetrável. Sinto que, ao cruzar a cancela, não estarei entrando em algum lugar, mas saindo de todos os outros. Dali avisto todo o vale e seus limites, mas ainda assim é como se o vale cercasse o mundo e eu agora entrasse num lado de fora. Após a besta hesitação, percebo que é esse mesmo o meu desejo (Buarque, 1991, p. 24).

A invasão do sítio priva o narrador da perspectiva redentora do apagamento e autonegação, cristalizando-se numa fuga de todos os lugares. Ironicamente, no único momento em que ele revela uma vontade de envolvimento com o mundo exterior quando foge do sítio depois da execução dos marginais no final da narrativa - o seu gesto é interpretado pelo desconhecido no ponto de ônibus como ameaça e resulta na morte do protagonista.

\section{BUDAPESTE (2003)}

O protagonista do romance de 2003 é um bem-sucedido ghostwriter carioca que procura construir uma vida nova na capital húngara, apaixonando-se pela língua, e em seguida pela sua professora, Kriska. Como já se pretendeu mostrar no início do presente artigo, o seu primeiro contato com a cidade revela traços de uma impressão onírica, sendo a cidade descrita como "amarela". Quando José Costa regressa a Budapeste, a sua impressão do espaço muda: "Nascia um dia nebuloso e a cidade era cinzenta; engraçado que eu imaginava Budapeste amarela, mas era toda cinzenta, os edifícios, os parques, até o Danúbio que a cortava em forma de ípsilon, bifurcando-se no alto" (Buarque, [2003] 2008, p. 41). Como se vê, o protagonista se 
deixa afetar pelo espaço, mas o seu próprio estado de espírito e disposição também afetam sua percepção. Importa salientar que também nessa cena a percepção do protagonista é perturbada, desta vez em consequência do álcool consumido ao longo da noite em companhia de dois romenos. Altera-se, no entanto, o papel das nuvens, que no trecho supracitado já não funcionam como uma moldura que deturpa a imagem, como durante o primeiro lance de olhos feito pela janela do avião.

Percebe-se também que para José Costa o espaço urbano representa uma paisagem homogênea e generalizada - seja amarela ou cinzenta - o que se traduz pela falta de envolvimento direto com a cidade. $\mathrm{O}$ personagem principal desse romance, em que há poucas referências a lugares específicos na capital húngara, evita uma experiência imediata com o espaço urbano. Ele valoriza antes um contato mediado pelos signos. Como comenta: "Custei a aprender que para conhecer uma cidade, melhor que percorrê-la em ônibus de dois andares é se fechar num aposento dentro dele" (Buarque, [2003] 2008, p. 38). Por isso, o protagonista desiste de uma excursão turística, isola-se num quarto de hotel e estuda o mapa, que para ele equivale ao conhecimento da cidade:

E ao longo do dia, esquadrinhei ruas e becos de Buda, andei com desenvoltura por cima de sua muralha, entrei pelas paredes do castelo medieval. Não me aborrecia caminhar assim num mapa, talvez porque sempre tive a vaga sensação de ser eu também o mapa de uma pessoa (Buarque, [2003] 2008, p. 46).

A situação não é alterada nem quando ele começa a estudar a língua. Em vez de aproveitar a oportunidade de praticar seus conhecimentos do idioma na realidade coletiva da urbe, ele se entrega a uma relação afetiva com sua professora húngara: "Um mês em Budapeste, na verdade, significava um mês com Kriska, porque sem ela eu evitava me aventurar na cidade; receava perder, no vozerio da cidade, o fio de um idioma que vislumbrava apenas pela sua voz" (Buarque, [2003] 2008, p. 52-53). Entende-se, portanto, que o interesse do protagonista pela alteridade não se orienta para a cidade em si, mas antes para a língua enquanto representação simbólica. Mesmo quando revisita lugares que possuem uma carga emotiva importante, ele desliza para recordações linguísticas:

(...) ao entrar na nossa rua [onde morou com Kriska - G.B.], de longe avistei a vila de casas gêmeas, e entre dezenas de telhados idênticos, distingui a meia-água que me abrigara por tantos anos. E me lembrei de Kriska na soleira, a me receber pela primeira vez: Zsoze Kósta... Zsoze Kósta... Em pensamento respondi: aí estou chegando quase, bela, branca, cigarros Fecske, mesa, café, patins, bicicleta, janela, peteca, alegria, um, dois, três, nove, dez, e caí em mim (...) (Buarque, [2003] 2008, p. 119).

Quando no final do romance o protagonista consegue finalmente se estabelecer em Budapeste, é só devido a um ghostwriter húngaro que escreve na língua magiar 
um romance autobiográfico em que relata a experiência de José. $\mathrm{O}$ brasileiro acaba por assumir a obra por sua, reconhecendo-se na ficção alheia. A criação de vínculos estáveis com o espaço dá-se, portanto, através da representação simbólica e só a custa da identidade anterior do personagem.

\section{LEITE DERRAMADO (2009)}

No penúltimo romance de Chico Buarque, a ligação entre o espaço e a identidade se manifesta de forma muito explícita, conjugando-se habilmente com a dimensão temporal da subjetividade. A autonarrativa - confusa, aparentemente desorganizada, dividida em 23 capítulos de um parágrafo único - é enunciada por Eulálio Montenegro d'Assumpção, filho do senador da Primeira República. Eulálio, um centenário que se encontra num leito de hospital devido à fratura do fêmur, urde suas lembranças em torno da peça-chave representada por Matilde, sua mulher, que desapareceu há muitos anos sem nenhuma razão explícita.

Uma vez que o narrador se acha internado no hospital e sua percepção presente é reduzida a um lugar muito limitado, a sua subjetividade evoca vários espaços em que se realizou a experiência passada. A importância da dimensão espacial é perceptível na seguinte passagem que pode servir uma das chaves interpretativas para a compreensão da obra:

Em tempos encontrei certo coronel num corredor sombrio do hospital do Exército. Ele afirmou que estivera comigo quando ainda era terceiro-sargento, mas seu rosto na penumbra não me dizia grande coisa. (...) Ia me despedir quando ele mencionou as provas de artilharia na Marambaia, e não sei por que não o fez desde o início, num instante tudo se iluminou. Seria mesmo inútil revirar arquivos de nomes e rostos, porque minha memória tinha guardado o sargento na paisagem (Buarque, 2009, p. 55-56).

Assim sendo, embora ele afirme que "a memória é deveras um pandemônio" (Buarque, 2009, p. 55), a ordenação do confuso universo das recordações eulalianas é possível desde que se atente para a dimensão espacial (representada no trecho supracitado pela "paisagem") da memória do protagonista. Esta topografia mnemônica compreenderia sobretudo três lugares: a fazenda na raiz da serra, terra do avô, relacionada com a infância do protagonista; o casarão em Botafogo, construído pelo pai de Eulálio, mas ligado principalmente à figura da mãe que aguarda o regresso do marido das viagens na Europa e dos encontros com outras mulheres; e o chalé em Copacabana, construído pelo avô, onde Eulálio mora com a sua esposa, Matilde, depois do casamento, passando ali os anos mais felizes da vida. O lugar fica impregnado pela presença da esposa, de modo que o narrador teme que "noutro 
lugar talvez [...] não ouvisse mais os suspiros dela, naquele endereço ela ainda vinha [lhe] ver em sonhos" (Buarque, 2009, p. 142).

Entende-se, porém, que essa geografia privada não passa de uma topografia afetiva e espectral, já que os espaços evocados pelo narrador no momento de enunciação já deixaram de existir. $\mathrm{O}$ casarão em Botafogo é cedido à embaixada da Dinamarca, e depois destruído, dando lugar para a construção de um centro médico. O chalé em Copacabana, com a qual Eulálio se identifica até ao ponto de declarar que "quando [ele] morrer, [seu] chalé cairá [com ele]" (Buarque, 2009, p. 63), foi vendido. Eulálio se esquece muitas vezes de ter se mudado para um edifício atrás do seu terreno, de onde assistiu à demolição do chalé e à construção de um prédio modernista, erguido em cima dos escombros da sua vida privada:

(...) vi cheio de pudor meu quarto com Matilde destelhado, vi ruir nossa laje, nossas paredes se desmanchando em pó e as fundações quebradas à picareta. No lugar dele subiu um edifício modernista, e tomei por uma delicadeza do arquiteto a construção suspensa sobre pilotis, para não soterrar de vez minhas recordações (Buarque, 2009, p. 174).

O protagonista muitas vezes não se lembra da desapropriação da fazenda, onde pretende se asilar depois da estada no hospital. Esquece-se também do seu doloroso regresso ao sítio, quando, já velho e empobrecido, aceita o convite de um pastor para se mudar para uma casa de um só cômodo, construída em cima da propriedade da sua família:

O valão era um rio quase estagnado de tão lamacento, quando se deslocava dava a impressão de arrastar consigo as margens imundas. Era um rio podre, contudo eu ainda via alguma graça ali onde ele fazia a curva, no modo peculiar daquela curva, penso que a curva é o gesto de um rio. E assim o reconheci, como às vezes se reconhece num homem velho o trejeito infantil, mais lento apenas. Aquele era o ribeirão da minha fazenda na raiz da serra. E à beira-rio uma mangueira me pareceu tão familiar, que por pouco e não ouvia o preto Balbino lá no alto; ó Lalá, vai querer manga, ó Lalá? Adiante a casa amarela, com o letreiro Igreja do Terceiro Templo na fachada, estava erguida provavelmente sobre os escombros da capela que o cardeal arcebispo abençoou em mil oitocentos e lá vai fumaça. E ao estar na casinha ao lado da igreja, me trouxe certo conforto saber que debaixo do meu chão estava o cemitério onde meu avô repousava (Buarque, 2009, p. 203-204).

Apesar de ocuparem no mesmo território físico, o local da infância e da velhice possuem marcas afetivas opostas: a "fazenda da [sua] feliz infância" (Buarque, 2009, p. 9) coincide com o bairro pobre construído mais tarde, que chama de "cafundós" (Buarque, 2009, p. 64) ou "um endereço de gente desclassificada" (Buarque, 2009, p. 160). 


\section{CONSIDERAÇÕES FINAIS}

Como se pretendeu mostrar, as representações do espaço nas autonarrativas buarqueanas sublinham a dimensão afetiva da relação do sujeito com o local. O protagonista de Estorvo renuncia a criação de vínculos identitários com o espaço (tanto físico, como social), optando por uma fuga incessante. Quando perde sua única salvação, representada pelo sítio da família capaz de isolá-lo do "aqui e agora" em que a sua subjetividade se acha condenada a operar, e tenta se envolver com o mundo exterior, encontra a morte. No romance Budapeste, José Costa evita a experiência imediata com a sua nova pátria e se fecha em um universo de signos e representações, tornando-se, no final, uma representação de si mesmo. Para Eulálio, o narrador de Leite derramado internado num quarto minúsculo do hospital, o espaço existe só na medida em que é lembrado, e a lembrança, apesar da passagem do tempo, é capaz de guardar o espaço dentro da subjetividade. Com essas e outras figuras Chico Buarque conseguiu esboçar as topografias afetivas dos seus personagens, sujeitos deambulantes e delirantes que experienciam o espaço urbano contemporâneo em sua intensidade emotiva. 


\section{BIBLIOGRAFIA}

Almeida, S.R.G. (2015). Mobilidades culturais, geografias afetivas: espaço urbano e gênero na literatura contemporânea. In R. Dalcastagnè, V.M. Vasconcelos Leal (Eds.), Espaço e gênero na literatura brasileira contemporânea (pp. 15-39). Porto Alegre: Zouk.

Anderson, D. (2017). Affective Topographies: Landscape and Subjectivity in the Work of Patrick Keiller, W.G. Sebald and Iain Sinclair. London: University College London.

Borowski, G. (2012). Identidades perturbadas num distúrbio pós-moderno: Estorvo de Chico Buarque. In R. Díaz-Szmidt (Ed.), Identidades revisitadas, identidades reinventadas: transformações dos espaços sociais, políticos e culturais nos países de língua oficial portuguesa (pp. 153-171). Varsóvia: Muzeum Historii Polskiego Ruchu Ludowego; Instytut Studiów Iberyjskich i Iberoamerykańskich UW.

Buarque, Ch. (1991). Estorvo. Lisboa: Dom Quixote.

Buarque, Ch. (1997). Benjamim. Lisboa: Presença.

Buarque, Ch. (2008). Budapeste. Alfragide: Leya.

Buarque, Ch. (2009). Leite derramado. Alfragide: Dom Quixote.

Buarque, Ch. (2014). O irmão alemão. São Paulo: Companhia das Letras.

Certeau, M. (1998). A invenção do cotidiano: artes de fazer (trans. E. Ferreira Alves). Petrópolis: Vozes.

Etymonline (2019). Affect. In Online Etymology Dictionary. Retrieved April, 29 from https://www. etymonline.com/word/affect.

Jo, J.Y.O. (2018). Homing: An Affective Topography of Ethnic Korean Return Migration. Honolulu: University of Hawai'i Press.

Leys, R. (2011). The Turn to Affect: A Critique. Critical Inquiry, 37, 434-472. DOI: $10.1086 / 659353$.

Massumi, B. (1995). The Autonomy of Affect. Cultural Critique, 31, 83-109. DOI: $10.2307 / 1354446$.

Nader, L. (2014a). Afekt. In M. Saryusz-Wolska, R. Traba (Eds.), Modi memorandi: leksykon kultury pamięci (pp. 31-33). Warszawa: Scholar.

Nader, L. (2014b). Afektywna historia sztuki. Teksty Drugie, 1, 14-40.

Nogueira, R.C. (2005). Fragmentos urbanos imaginados. Testos e Pretextos, 7, 60-71.

Nycz, R. (2014). Afektywne manifesty. Teksty Drugie, 1, 9-13.

Peres, A.M.C. (2016). Conversa com Chico Buarque. In Chico Buarque: recortes e passagens (pp. 189-208). Belo Horizonte: Editora da UFMG.

Rybicka, E. (2006). Geopoetyka (o mieście, przestrzeni i miejscu we współczesnych teoriach i praktykach kulturowych). In M.P. Markowski, R. Nycz (Eds.), Kulturowa teoria literatury: główne pojęcia i problemy (pp. 471-490). Kraków: Universitas.

Silva, F.B. (2004). Chico Buarque. São Paulo: Publifolha.

Thrift, N. (2004). Intensities of Feeling: Towards a Spatial Politics of Affect. Geografiska Annaler, 86, 57-78. DOI: 10.1111/j.0435-3684.2004.00154.x.

Walker, I. (2002). City Gorged with Dreams: Surrealism and documentary photography in interwar Paris. Manchester/New York: Manchester University Press. 